\title{
Evaluation of Poverty Alleviation Performance from the Perspective of SPSS Data Analysis of Intergenerational Mobility
}

\author{
Zhou Haonan $^{1, a}$, Xie Kexin²
}

\author{
${ }^{1}$ Sichuan Agricultural University, Chengdu, Sichuan, China \\ ${ }^{2}$ Sichuan Agricultural University, Chengdu, Sichuan, China \\ zhouhaonan@stu.sicau.edu.cn, azhouhaonan99@163.com
}

\begin{abstract}
:
In recent years, my country's poverty alleviation mission will gradually shift from "eliminating absolute poverty" to "reducing relative poverty." However, under this transition, how can we evaluate the performance of poverty alleviation more scientifically? Based on the SPSS data analysis software, this paper analyzes the problems of the existing poverty alleviation performance evaluation system from the perspective of intergenerational mobility, and uses the quantitative regression analysis method to intelligently digitize the poverty alleviation performance. Data analysis shows that the factors affecting intergenerational mobility have a positive correlation with poverty alleviation performance. Among them, the education level of children has the most significant impact on poverty alleviation performance. Therefore, relevant suggestions are made based on the analysis results.
\end{abstract}

Keywords : Intergenerational mobility; Poverty reduction performance; The empirical research; Education

\section{INTRODUCTION}

In recent years, my country's rural areas have entered a new stage of poverty alleviation centered around targeted poverty alleviation, and poverty alleviation work has been steadily advancing. In this battle of poverty alleviation, Chengdu, as the "backbone" of Sichuan province, has always been at the forefront of poverty alleviation work. The main task of poverty alleviation in our country will gradually change from "eliminating absolute poverty" to "reducing relative poverty", from "figure food and clothing" to "figure development", and from static poverty alleviation to preventing dynamic return to poverty. Promoting social intergenerational mobility and preventing intergenerational transmission of poverty are at the core of the above transformation. This article takes the poverty-stricken villages in Chengdu as a reference object. First, based on the literature review, it analyzes the outstanding problems in the current poverty-alleviation performance evaluation system. Second, it uses the quantitative regression method to empirically study and analyze the poverty-stricken villages in Chengdu from a cost flow perspective Poverty alleviation performance; finally, based on the results of empirical research, we provide policy recommendations for further improving the long-term poverty alleviation mechanism in Chengdu.

\section{Problems IN THE EXISTING POVERTY ALLEVIATION PERFORMANCE EVALUATION SYSTEM}

Most of the existing literature on poverty alleviation performance evaluation systems at home and abroad, based on the analytic hierarchy process, construct performance evaluation systems from different perspectives such as targeted poverty alleviation, participatory poverty alleviation, financial poverty alleviation, and tourism poverty alleviation. The existing research has the following characteristics: First, the research scope is wide. Second, the research content is relatively comprehensive. Third, scholars are constantly deepening the application of empirical research methods. Despite this, scholars are still exploring the evaluation system for poverty alleviation performance, and the research still needs to be improved, specifically in the following aspects: 


\subsection{Poverty alleviation performance evaluation method needs to be scientific}

The current poverty alleviation performance evaluation method focuses on the evaluation of poverty alleviation funds investment and fund management, and mostly uses the macro level to evaluate the economic and social benefits of poverty alleviation. There is no more micro-level judgment on the poverty alleviation performance of families and individuals. There is a lack of individual Targeted. This evaluation standard only focuses on the two indicators of the reduction progress of the absolute poor population and the reduction progress of the low-income poverty population that year ${ }^{[1]}$, and lacks the concern about the sustainable growth of the income of poor households in the future, nor does it take into account the current poverty alleviation of poverty-stricken households may return to poverty due to their ability to resist risks and lack their own development capabilities. Among them, the ability of self-development emphasizes that the poor need to receive certain theoretical and cultural education and practical skills training, and possess certain knowledge and skills to acquire and use social resources to realize their own value; the ability to sustainably increase economic income means to use The long-term and sustainable perspective focuses on the income growth of the poor, rather than short-term growth. Therefore, the current poverty alleviation performance evaluation should change from "economic goal orientation" to "ability orientation" to achieve sustainable development.

\subsection{The construction of poverty alleviation performance evaluation system lacks dynamic}

With the advancement of poverty alleviation work, the poverty alleviation tasks and related policies issued by our country are constantly changing with the trend of the times, that is, from static poverty alleviation to prevention of dynamic return to poverty. The current poverty alleviation performance evaluation system focuses on the static evaluation of poverty alleviation performance, focusing on the short-term "digital poverty alleviation" surface effects, emphasizing the analysis of the current causes of poverty, and paying little attention to the dynamic analysis of poverty between generations There is a lack of long-term evaluation of the poor people's self-development ability shaping process and poverty alleviation effect. However, the poverty problem in our country is long-term, arduous and complicated. Therefore, it is necessary to establish and improve a long-term mechanism for poverty alleviation and poverty alleviation to prevent the emergence of "poverty black holes" and the phenomenon of returning to poverty. Therefore, it is very necessary and meaningful to construct a dynamic poverty alleviation performance evaluation system.

\subsection{Methods and perspectives for the construction of performance evaluation systems need to be diversified}

Through combing the literature, we found that in the existing research, most scholars used statistical methods to construct and improve the performance evaluation system. Among them, most studies use the analytic hierarchy process (The analytic hierarchy process) to analyze and evaluate the system, but rarely use other methods, such as regression analysis, TOPSIS method and entropy weight method. Based on this, we also found that scholars still have some unity and limitations in the construction of the poverty alleviation performance evaluation system. Especially from the perspective of intergenerational mobility, there is still a gap in the research on the construction of the poverty alleviation performance evaluation system, and there are few relevant documents. Therefore, we believe that in future research, the research perspective can be broadened, and diversified evaluation methods can be used to enrich the construction model of the poverty alleviation performance evaluation system and provide a research core for further exploration of the poverty alleviation performance evaluation system.

\section{THE SIGNIFICANCE AND ROLE OF EVALUATING POVERTY ALLEVIATION PERFORMANCE FROM THE PERSPECTIVE OF INTERGENERATIONAL MOBILITY}

\subsection{Utilizing intergenerational mobility to optimize poverty alleviation performance evaluation methods}

Intergenerational mobility is the key to optimizing evaluation methods in performance evaluation. According to the concept and influencing factors of intergenerational transmission of poverty, the self-development ability such as education level, vocational skill status, etc. has an important influence on intergenerational transmission of poverty. Therefore, from the perspective of intergenerational mobility, by grasping the basic information of poor families and individuals, to understand the family structure, occupational nature, income and expenditure status, education level, and poverty-causing factors of the poor, more emphasis is placed on the income growth after poverty Sustainability, self-development ability, anti-poverty and anti-risk capabilities, and more targeted judgments on poverty alleviation performance of families and individuals from the micro level, can deeply analyze the underlying causes and laws behind the appearance of poverty, and adopt targeted poverty alleviation measures, Promote the maximization of poverty alleviation benefits. 


\subsection{Using intergenerational mobility to grasp dynamic poverty alleviation performance}

Intergenerational mobility is the basis for dynamic analysis in performance evaluation. Contemporary family eradication of absolute poverty is a short-term effect, while reducing relative poverty is a long-term task. Poverty alleviation performance evaluation from the perspective of intergenerational mobility is a dynamic evaluation of poverty alleviation performance by comparing generation-to-generation poverty alleviation performance. Compared with the current static poverty alleviation performance evaluation system, that is, the evaluation of absolute poverty alleviation effects, compared with Pay more attention to the long-term and dynamic analysis of intergenerational transmission of poverty, not just limited to the short-term "digital poverty alleviation" surface effect. Therefore, evaluating poverty alleviation performance from the perspective of intergenerational mobility is conducive to demonstrating the effectiveness of poverty alleviation performance over time. It is also conducive to dynamically grasping poverty alleviation performance and establishing a sound long-term poverty alleviation mechanism.

\subsection{Use intergenerational mobility to broaden the perspective of poverty alleviation performance evaluation system}

Intergenerational mobility is a way to broaden the perspective of the evaluation system in performance evaluation. The intergenerational flow perspective is a new perspective, and it is also a difficult perspective to measure. In the existing poverty alleviation performance evaluation system, very little literature involves evaluating poverty alleviation performance from the perspective of intergenerational mobility. Therefore, the combination of intergenerational mobility and poverty alleviation performance evaluation, and the use of regression analysis methods that are rarely used in the evaluation system research, is undoubtedly a major innovation in the perspective and method of performance evaluation. At the same time, it fills the gap in the research of the system. It can be seen that the use of intergenerational perspectives to evaluate poverty alleviation performance not only provides diversified research perspectives and research methods, but also provides reference and guidance significance for further exploring the poverty alleviation performance evaluation system.

\section{EVALUATE POVERTY ALLEVIATION PERFORMANCE BASED ON EMPIRICAL MEASUREMENT REGRESSION FROM THE PERSPECTIVE OF INTERGENERATIONAL MOBILITY}

\subsection{Sample selection and data sources}

The samples used for empirical research should be typical. China is in a new stage of poverty alleviation, and poverty alleviation work presents a complex situation. The selection of samples should grasp the current mainstream of poverty alleviation and development. Chengdu city of Sichuan Province has always been in the forefront of poverty alleviation, so we can grasp the trend of China's poverty alleviation in the new stage, especially from "eliminating absolute poverty" to "reducing relative poverty".

The author conducted a questionnaire survey in Jianyang city and Xinjin County, Chengdu. A total of 500 questionnaires were distributed, and 334 questionnaires were recovered. 276 respondents whose parents had registered poor households were selected as samples for empirical research. After screening, a total of 1,932 observed values were obtained. Some data of poverty alleviation performance were obtained by consulting China statistical Yearbook and combining with questionnaires to improve the data.

\subsection{Index system design}

\subsubsection{Indicators affecting factors of intergenerational mobility}

There are many factors that affect intergenerational mobility, such as factors related to cultural behavior, factors related to policy, factors related to economic structure (Stenberg, 2000), congenital factors (Herbert·J.Gans), household income factors (Lin Mingang, Zhang Ruili, 2012), educational factors (Zhang Lidong, 2013; Zhu Jianhua, 2016; Wang Zhaoxin, 2019), etc. Regarding the availability of data and the characteristics of this study, we will draw on the research of Bi Yan and Gao Lingzhi (2009), through the family members'occupational nature, children's education level, family members' education level, family members' per capita annual income There are four aspects to measure the factors affecting intergenerational mobility.

Considering whether the aforementioned influencing factors have relevance, applicability and reliability in poverty alleviation performance, we conducted factor analysis, validity analysis and reliability analysis. According to the questionnaire data, use spss software for reliability analysis, KMO and Bartlett's test, the results are shown in TableI. The overall Cronbach's $\alpha$ factor affecting the intergenerational flow factor is 0.722 , 
indicating that the index has good consistency; the KMO value is 0.698 , which is close to 1 , indicating that these data are suitable for factor analysis. At the same time, the Sig value in the Tartlett sphericity test is 0.000 , which is less than the significance level of 0.05. Passing the significance level test indicates that there is a correlation between the variables and factor analysis can be done.

TABLE I . KMO AND BARTLETT'S TEST

\begin{tabular}{lll}
\hline $\begin{array}{l}\text { A Kaiser-Meyer-Olkin metric with } \\
\text { sufficient sampling. }\end{array}$ & 0.698 \\
$\begin{array}{l}\text { Bartlett's } \\
\text { sphericity test }\end{array}$ & $\begin{array}{l}\text { Approximate } \\
\text { chi-square }\end{array}$ & 566.726 \\
& $d f$ & 21 \\
& Sig. & 0.000 \\
\hline \hline
\end{tabular}

\subsubsection{Evaluation indicators of poverty alleviation performance}

Scholars have established different poverty alleviation performance evaluation systems based on econometric models and poverty alleviation models. Gao Bo and Wang Shanping built a comprehensive performance evaluation system from the use of funds compliance, utilization rate, and use effect ${ }^{[2]}$; $\mathrm{Li} \mathrm{Yi}$ evaluated the performance of poverty alleviation and development from three aspects of economy, politics, and ecology ${ }^{[3]}$; Zhuang Tianhui and Zhang Haixia started from the level of food and clothing , Production and living conditions, ecological environment and development capabilities in four aspects to build a comprehensive performance evaluation index system for anti-poverty in southwest minority areas ${ }^{[4]}$. Based on the above research and the focus of this research, this article will use the per capita annual income indicators of children to evaluate poverty alleviation performance.

\subsection{Model building}

From the previous analysis, it can be seen that the factors affecting intergenerational mobility include family members' occupational nature, children's education level, family members' education level, and family members' per capita annual income. In order to test whether the above four factors affect poverty alleviation performance. To this end, the following model is established using one-dimensional linear equation:

$$
\alpha+\beta_{1} X_{i}+e=y
$$

$\mathrm{y}$ is the explanatory variable: poverty alleviation performance indicator; $\mathrm{X}_{\mathrm{i}}$ is the explanatory variable: the indicator affecting intergenerational mobility factors $(\mathrm{i}=1-4)$

$\beta_{1}$ is the coefficient corresponding to $\mathrm{Xi}$. When the coefficient is greater than zero, it indicates that the factor is positively correlated with poverty alleviation performance; when the coefficient is less than zero, it indicates that the factor is negatively correlated with poverty alleviation performance; e is the error.

\subsection{Empirical analysis}

\subsubsection{Regression analysis of family members' occupational nature and poverty alleviation performance}

The regression and test results are shown in TableII

TABLEII. REGRESSION ANALYSIS OF OCCUPATIONAL NATURE OF FAMILY MEMBERS AND POVERTY ALLEVIATION PERFORMANCE

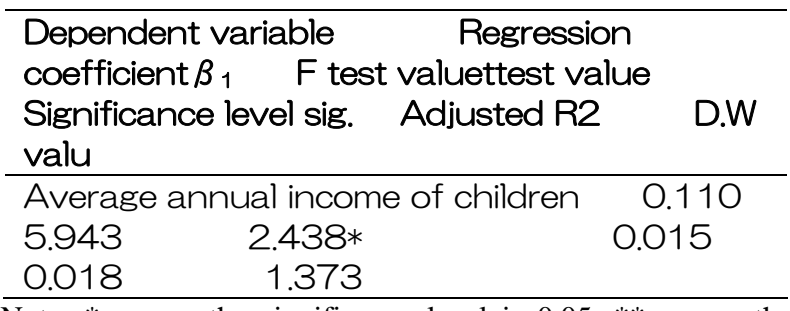

Note: * means the significance level is $0.05, * *$ means the significance level is 0.01 .

It can be seen from Table 2 that the correlation coefficient between the occupational nature of family members and the per capita annual income of children is positive. After the significance test of the regression coefficient, it is found that the t-test value of the family member's occupational nature and the child's per capita annual income has passed the 0.05 significance level test, that is, the family member's occupational nature and poverty alleviation performance evaluation index exist at the 0.05 significance level Positive relationship. The more stable the occupational nature of family members and the higher their social status, the better the poverty alleviation performance.

\subsubsection{Regression analysis of children's education level and poverty alleviation performance}

The regression and test results are shown in TableIII

TABLE III. REGRESSION ANALYSIS OF CHILDREN'S EDUCATION LEVEL AND POVERTY ALLEVIATION PERFORMANCE

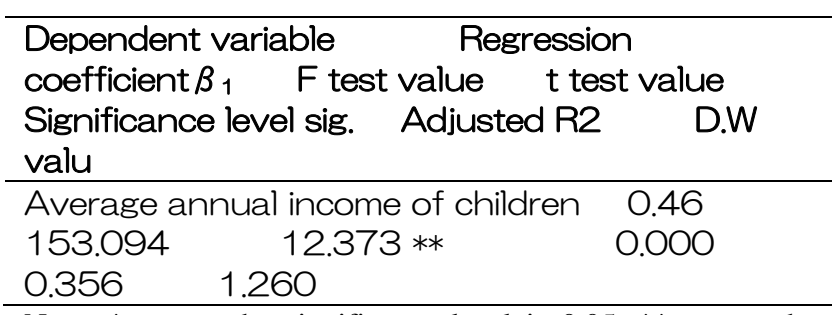

Note: * means the significance level is 0.05 , ** means the significance level is 0.01 .

It can be seen from Table 3 that there is a positive 
correlation between the education level of the children and the poverty alleviation performance evaluation index at the 0.01 significance level. The higher the education level of the children, the better the poverty alleviation performance.

\subsubsection{Regression analysis of family members' education level and poverty alleviation performance}

The regression and test results are shown in TableIV

TABLE IV. REGRESSION ANALYSIS OF FAMILY MEMBERS' EDUCATION LEVEL AND POVERTY ALLEVIATION PERFORMANCE

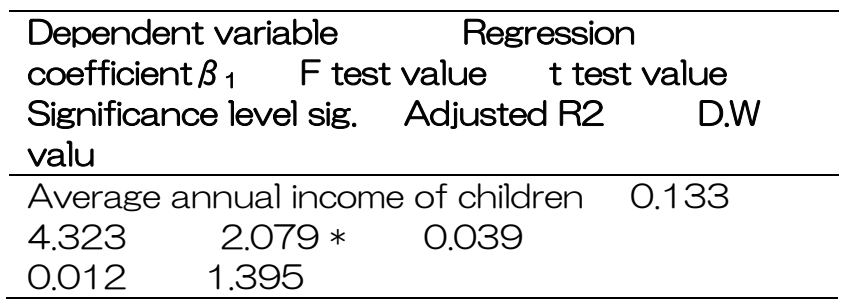

Note: * means the significance level is $0.05, * *$ means the significance level is 0.01 .

It can be seen from Table 4 that there is a positive correlation between the education level of family members and the poverty alleviation performance evaluation index at a significance level of 0.05 . The higher the education level of family members, the better the poverty alleviation performance.

\subsubsection{Regression analysis of family members' per capita annual income and poverty alleviation performance}

The regression and test results are shown in Table $\mathrm{V}$

TABLEV. REgRESSION ANALYSIS OF THE PER CAPITA ANNUAL INCOME OF FAMILY MEMBERS AND POVERTY ALLEVIATION PERFORMANCE

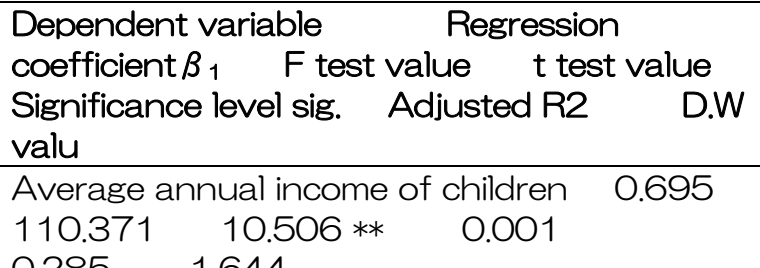
$0.285 \quad 1.644$

Note: * means the significance level is $0.05, * *$ means the significance level is 0.01 .

It can be seen from Table 5 that there is a positive correlation between the average annual income of family members and the poverty alleviation performance evaluation index at the 0.01 significance level. The higher the per capita annual income of family members, the better the poverty alleviation performance.

\subsection{Empirical analysis}

From the regression results, the four selected factors that affect intergenerational mobility have a significant impact on poverty alleviation performance. Among them, the influence of children's education level on poverty alleviation performance is the most significant among all explanatory variables. This may be because education has unique advantages in the development of poverty alleviation: First, education promotes the vertical flow of poor people, providing the possibility of cutting off the vicious circle of poverty; second, the key to poverty alleviation is the improvement of anti-poverty ability, not It only includes basic life ability, and more importantly, self-development ability and the improvement of the comprehensive quality of adapting to society. Therefore, in the long run, only by using education as the main means of poverty alleviation can we achieve sustainable development of poverty alleviation.

\section{CONCLUSION}

According to the above regression analysis results, we can know that the factors that affect intergenerational mobility will also affect poverty alleviation performance. China's poverty alleviation work has begun to enter a new stage, and the direction of poverty alleviation should be adjusted in time according to the priorities of social development and poverty alleviation tasks. For the new poverty alleviation task, the key lies in supporting people. Therefore, while providing economic assistance to poor families, such as economic assistance, it is necessary to increase financial investment in education resources and employment training, and improve and implement relevant policies. Only when education poverty alleviation is combined with economic poverty alleviation and the two methods complement each other, will our country's poverty alleviation work achieve better results.

\section{ACKNOWLEDGMENTS}

Special thanks to Sichuan Agricultural University 2019 Research Interest Training Program project "Poverty Alleviation Performance Evaluation from the Perspective of Intergenerational Mobility -- A Case Study of Chengdu" (2020846).

Special thanks to Duan Yide, professor of asset Appraisal Department, Business School, Sichuan Agricultural University.

Disclaimer: This article has been modified slightly.

\section{REFERENCES}

[1] Wang Shanping, Gao Bo. Research on the corporatization operation of financial poverty 
alleviation funds [J]. Research on Financial Problems, 2012, 000(011): 77-82.

[2] Gao Bo, Wang Shanping. Research on Comprehensive Performance Evaluation System of Financial Poverty Alleviation Funds [J]. Yunnan Sociology, 2014,000(005): 86-89.

[3] Li Yi, Ge Guoyao. Poverty Alleviation Development Performance Evaluation Index System and Empirical Application [J]. Economic and Social Development, 2018, 016(001): 49-54.

[4] Zhang Haixia, Zhuang Tianhui. Research on performance evaluation of non-governmental organizations participating in poverty alleviation_ A case study on performance evaluation of NGO Involved in Poverty Alleviation-A case study on Development Organization of Rural Sichuan[J] . Development Research, 2010, 000(003): 55-60.

[5] Gao Bo, Wang Shanping. To improve the anti-poverty ability orientation of financial poverty alleviation funds [N]. Guangming Daily (Theoretical Edition), 2014-02-16.

[6] Li Xiaoming. Review of the theory of intergenerational transmission of poverty [J]. Journal of Guangxi Youth Cadre College, 2006(02):75-78+84.

[7] Sten-Ake Stenberg, (2000), Inheritance of Welfare Re-cipiency: An Intergenerational Study of Social Assistance Recipi-ency in Postwar Sweden,"Journal of Marriage and Family62(1), P228-239.

[8] Zhang Lidong. An empirical study on the intergenerational transmission of rural poverty in China [J]. Chinese Population-Resources and Environment, 2013,23(06):45-50.

[9] Zhu Jianhua. Analysis of educational factors in the process of intergenerational transmission of poverty [J]. Education Development Research, 2016, 36(03): 36-44.

[10] Wang Zhaoxin. Unequal Childhood: A Literature Review of Education Equity in the Upward Movement of Rural Children [J]. Juvenile and Child Research,2019(08): 44-55.

[11] Bi Xuan, Gao Lingzhi. Analysis of influencing factors of intergenerational transmission of urban poverty_-Based on the perspective of social mobility theory[J]. Gansu Social Sciences, 2009(02):22-25. 